\title{
Prognostic significance of total platelet count with PICU outcome
}

\author{
Bisoi S. K ${ }^{1}$, Mohanty MD² \\ ${ }^{1}$ Dr Swarup Kumar Bisoi, ${ }^{2}$ Dr Mamata Devi Mohanty, both are affiliated with, Department of Pediatrics, IMS SUM \\ Hospital, Bhubaneswar, Odisha, India.
}

Address for Correspondence: Dr Swarup Kumar Bisoi, K-8 Kalinga Nagar, IMS SUM Hospital, Bhubaneswar, India. Email -drswarup@outlook.com,

\begin{abstract}
Background: Platelets in addition to their contribution in hemostasis are inflammatory cells having important role in host defense and can be of prognostic significance. Aim: Present study aims to evaluate the relationship of platelet, leucocyte count and $\mathrm{C}$ - reactive protein with outcome of cases admitted to Pediatric Intensive Care Unit (PICU). Material and Method: A prospective cohort study of 84 patients admitted for at least 3 days in the PICU at Institute of Medical Sciences and SUM Hospital, Bhubaneswar, India was undertaken from August 2015 to February 2016. Patient data related to socio-demographic profile, patient history, clinical features and investigational findings were recorded. Results: The mean platelet count on day of admission was 6.13 lakhs/cumm which decreased during the stay and showed significant positive correlation with the duration of PICU stay and death outcome. The change in platelet count during stay also showed significant association with death outcome. Significant correlation was observed between total leucocyte count and C-reactive protein with duration of stay. Also duration of stay is significantly associated with the death outcome. Conclusion: Platelet, leucocyte and C- reactive protein status on day of admission significantly correlates with duration of stay and death as outcome. Decreased platelet count during stay necessitates thorough evaluation of cases.
\end{abstract}

Keywords: Total Platelet Count (TPC), Total Leucocyte Count (TLC), Correlation, Duration of PICU stay, Outcome.

\section{Introduction}

Clinicians have always interpreted the degree of leucocytosis as an indication of systemic inflammatory response and severity of disease. In recent days platelets have been increasingly recognized as an important component of innate and adaptive immune system. Both leucocyte and platelet contain antimicrobial peptides that act against a broad range of pathogens that contributes to limiting the infection [1]. Platelet count is now being considered as a predictor of outcome in the ICU setting as an independent parameter [2]. It is found to be as good a predictor as the various mortality scores used in the ICU [3]. Platelet response in antimicrobial host defense is similar, in many ways, to the leucocyte response [4]. Thrombocytosis is common finding among the patients admitted in ICU. Extreme thrombocytosis should not be considered a rare event in a critical care hospital population and usually represents a reactive defense phenomenon [5]. Reactive

Manuscript received: $24^{\text {th }}$ April 2016

Reviewed: $7^{\text {th }}$ May 2016

Author Corrected; $20^{\text {th }}$ May 2016

Accepted for Publication: $4^{\text {th }}$ June 2016 thrombocytosis is usually mediated by increased release of numerous cytokines in response to infections, inflammation, vasculitis, tissue trauma, and other factors. Thrombopoietin, the primary cytokine for platelet production and maturation, and interleukin (IL)6 levels are usually initially elevated in response to the inflammation, stimulate an increased platelet production. However, serum or plasma levels of these cytokines do not seem to with degree of thrombocytosis [6]. Other cytokines such as stem cell factor, granulocyte macrophage colony stimulating factor, IL6 , IL-8 and IL-11 play a major role in certain steps of megakaryopoiesis and thrombopoiesis $[7,8]$. When the original stimulation stops, the platelet count then returns to the reference range.

Infections of the respiratory tract account for $60-80 \%$ of cases of secondary thrombocytosis in children, [9-14]. followed by infections of the urinary [15] and gastrointestinal tracts, and of the bones $[10,11,14,16]$. There is dearth of research studies exploring the 
relationship of change in platelet count with the PICU outcomes like mortality. Present study aims to understand the relationship of platelet count and its change over the period of hospital stay with the duration of PICU stay and patient outcome in terms of mortality. This will help us to prognosticate the cases using these simple investigations, without going through the cumbersome scoring systems.

\section{Methodology}

An observational cohort study was undertaken in the Pediatric Intensive Care Unit of Institute of Medical Sciences and SUM Hospital, Bhubaneswar, India over a period of 6 months from $1^{\text {st }}$ August 2015 to 1 st February 2016. A total of 84 admitted patients those admitted directly to pediatric intensive care unit (PICU) and stayed for at least 3 days were studied. Patient's demography, source of admission, primary diagnosis, presence or absence of sepsis, coagulopathy, use of central venous or arterial lines and mechanical ventilation were recorded.

Laboratory data collected include complete blood counts on day 1, 2 and 3 along with $\mathrm{C}$ - reactive protein, blood urea nitrogen and serum creatinine on day 1. Data collected on different variables were analyzed by using the SPSS version 20 software to find out the correlation between variables (Pearson's product correlation coefficient). $\mathrm{P}$ value of $<0.05$ was considered for statistical significance.

To find out the trend in change of platelet count with patient outcome (death), value of more than 4 lakhs/cumm, 1.5 to 4.0 lakhs/cumm and less than 1.5 lakhs/cumm was categorized as thrombocytosis, normal and thrombo-cytopenia respectively [17].

\section{Result}

Among the total 84 cases studied, 48 (57.1\%) were males and 36 (42.9\%) were females. The average duration of PICU stay among the cases was 6.57 days (range of $3-13$ days). The mean platelet count of patients on day of admission was 6.135 lakhs/cumm. The overall mortality among the cases getting admitted in PICU during the study period was found to be $35.7 \%$. The mean value of C-reactive protein investigated on the day of admission was $4.48 \mathrm{mg} / \mathrm{L}$. The value of mean total platelet count and total leucocyte count decreases progressively during the stay of the patients. The mean TPC on day of admission was 6.13 lakhs/cumm, which decreased by $24.9 \%$ by day 1 and $42.6 \%$ by day 2 . The mean and standard deviation of different parameters is given in table-1.

Table 1: Mean and Standard deviation of various parameters

\begin{tabular}{|l|l|l|}
\hline Variables & Mean & Standard deviation \\
\hline Age & 55.3 months & 42.8 \\
\hline TLC on day 1 & 21188 & 6689 \\
\hline TLC on day 2 & 17697 & 6173 \\
\hline TLC on day 3 & 15099 & 5761 \\
\hline TPC on day 1 & 6.13 lakh & 1.89 \\
\hline TPC day 2 & 4.60 lakh & 1.88 \\
\hline TPC on day 3 & 3.52 lakh & 1.37 \\
\hline CRP on day 1 & $4.48 \mathrm{mg} / \mathrm{L}$ & 4.17 \\
\hline PICU Stay & 6.6 days & 2.5 \\
\hline
\end{tabular}

Taking age and gender as the control variables, data shows there is statistically significant correlation between TPC (D1, $\mathrm{D} 2$ and D3) with duration of PICU stay $(\mathrm{P}<0.05)$. Also that there is significant positive correlation between TPC on D1 with death as patient outcome $\left(\mathrm{R}^{2}=0.232, \mathrm{p}<0.05\right)$, while no significant correlation was observed between TPC on $\mathrm{D} 2$ and D3 with patient outcome.

Significant positive correlation between differences in TPC measured with reference to day 1 of admission (D1-D2 and D1-D3) with duration of PICU stay $\left(\mathrm{R}^{2}=0.22,0.244\right.$ respectively, $\left.\mathrm{P}<0.05\right)$, but no such correlation was observed with D2-D3 TPC. Statistical significant correlation was found between patient outcome and the difference in TPC taken in reference to day1 i.e, D1-D2 and D1-D3 $\left(\mathrm{R}^{2}=0.288,0.289\right.$ respectively, $\left.\mathrm{P}<0.05\right)$. Other correlation with TPC is given in table-2. 
Table 2: Correlation of total platelet count on different days and change of platelet count with duration of PICU stay and mortality outcome.

\begin{tabular}{|l|l|l|l|l|}
\hline \multirow{2}{*}{ Variables } & \multicolumn{2}{|l|}{ PICU Stay } & \multicolumn{2}{l|}{ Outcome (Death) } \\
\cline { 2 - 5 } & Correlation coefficient $\left.\mathbf{( R}^{\mathbf{2}}\right)$ & P value & Correlation coefficient $\left(\mathbf{R}^{\mathbf{2}}\right)$ & P value \\
\hline TPC on Day 1 & .398 & .000 & .232 & .036 \\
\hline TPC on Day 2 & .255 & .021 & .018 & .874 \\
\hline TPC on Day 3 & .240 & .030 & -.048 & .668 \\
\hline $\begin{array}{l}\text { Difference in TPC } \\
\text { (Day 1 - Day 2) }\end{array}$ & .220 & .047 & .288 & .009 \\
\hline $\begin{array}{l}\text { Difference in TPC } \\
\text { (Day 1 - Day 3) }\end{array}$ & .244 & .027 & .289 & .008 \\
\hline $\begin{array}{l}\text { Difference in TPC } \\
\text { (Day 2- Day 3) }\end{array}$ & .091 & .419 & .085 & .449 \\
\hline
\end{tabular}

Considering age and gender as control variable, significant positive correlation was observed between TLC count (Day 1, 2 and 3) with duration of PICU stay ( $<<0.001)$ while no significant correlation was observed between difference in TLC count (D1 - D3) and duration of PICU stay. Statistically significant correlation was found between TLC (D1, 2 and 3) and death $(\mathrm{p}<0.05)$. Correlation of TLC with other indicators is given in table-3.

Table-3: Correlation of total leucocyte count on different days and difference of leucocyte count with days of PICU stay and outcome (death) of patients

\begin{tabular}{|l|l|l|l|l|}
\hline \multirow{2}{*}{ Variable } & \multicolumn{2}{l}{ PICU Stay } & Outcome & \multicolumn{2}{l|}{} \\
\cline { 2 - 5 } & Correlation coefficient $\left.\mathbf{( R}^{\mathbf{2}}\right)$ & P value & Correlation coefficient $\left.\mathbf{R}^{\mathbf{2}}\right)$ & P value \\
\hline TLC D1 & .495 & .000 & .238 & .032 \\
\hline TLC D2 & .557 & .000 & .361 & .001 \\
\hline TLC D3 & .540 & .000 & .388 & .000 \\
\hline Difference TLC & .031 & .784 & -.126 & .259 \\
\hline
\end{tabular}

Statistical significant correlation was observed between C-reactive protein on day1 and duration of PICU stay $\left(\mathrm{R}^{2}=\right.$ 0.464, $\mathrm{p}<0.001)$. C-reactive protein was also found to be positively associated with death $\left(\mathrm{R}^{2}=0.308, \mathrm{p}<0.01\right)$. A strong correlation was also observed between days of PICU stay with death of the patients $\left(\mathrm{R}^{2}=0.481, \mathrm{p}<0.001\right)$.

The change in total platelet count during initial three days of stay at PICU shows majority of cases had thrombocytosis $(85.7 \%)$ and there was a gradual decline in the total platelet count. The progress of cases to different categories (thrombocytosis, normal and thrombocytopenia) is depicted in table-5. The outcome result shows that the mortality rate was $38.7 \%, 20 \%$ and $76.9 \%$ among the thrombocytosis, normal and thrombocytopenia categories respectively based on their TPC on day 3.

Table 4: Correlation of C-reactive protein on day of admission with duration of PICU stay and patient outcome (death) and also correlation of duration of PICU stay with outcome (death).

\begin{tabular}{|l|l|l|l|l|}
\hline \multirow{2}{*}{ Variable } & \multicolumn{2}{|l|}{ PICU Stay } & \multicolumn{2}{l|}{ Outcome (Death) } \\
\cline { 2 - 5 } & Correlation coefficient $\left.\mathbf{( R}^{2}\right)$ & P value & Correlation coefficient $\left(\mathbf{R}^{2}\right)$ & P value \\
\hline $\begin{array}{l}\text { C- reactive protein } \\
\text { on day 1 }\end{array}$ & .464 & .000 & .308 & .005 \\
\hline PICU stay & - & - & .481 & .000 \\
\hline
\end{tabular}


Table -5: Progress of cases into different categories based on their TPC and the death outcome.

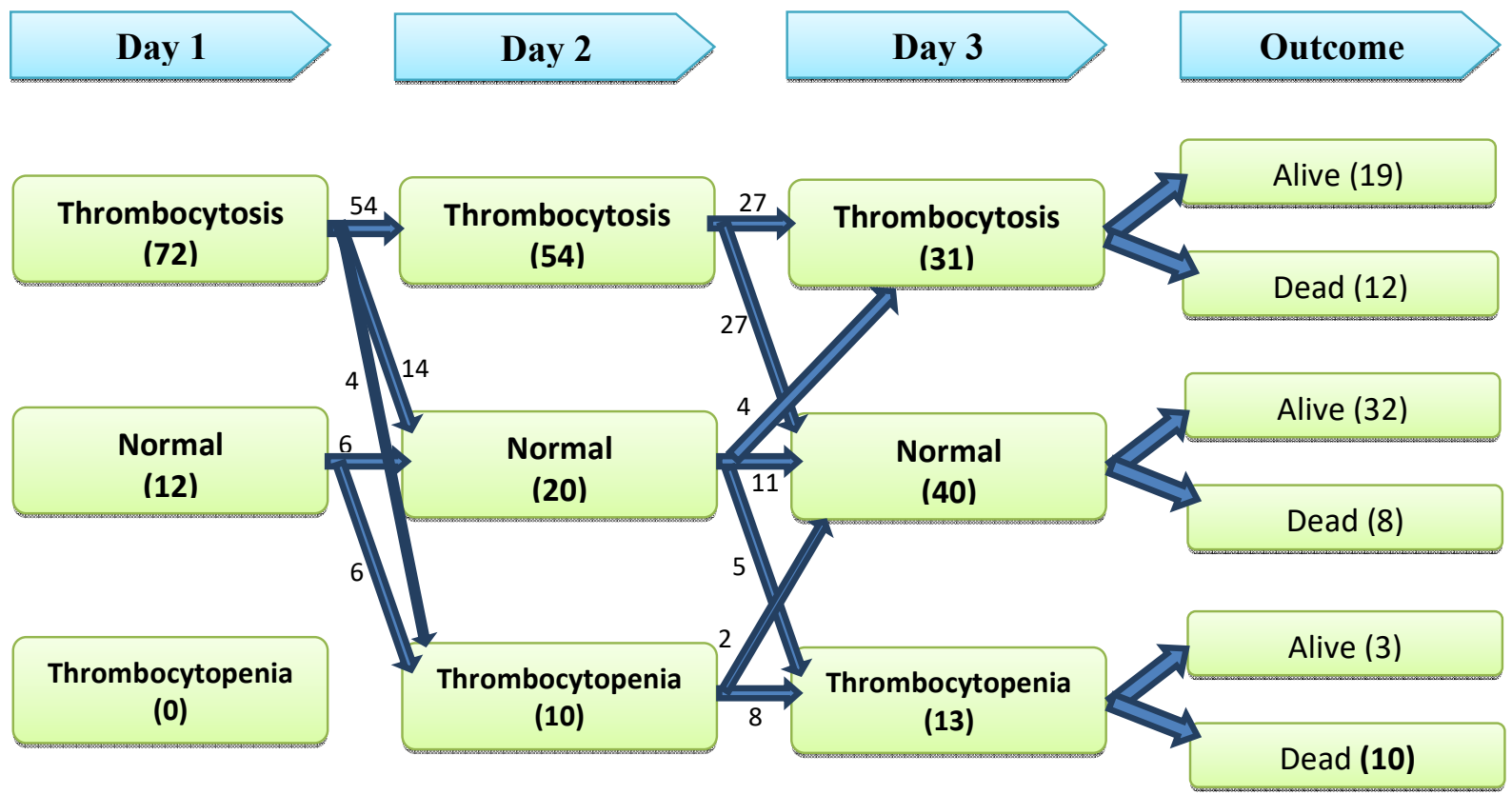

\section{Discussion}

Thrombocytosis is common investigational finding among the ICU patients. There are very few studies comparing platelets counts to duration of stay and overall outcome in Paediatric Intensive Care Unit. Russul. F et.al, found that the survivors had higher platelet counts throughout their Pediatric Intensive Care Unit stay, compared to non survivors. Also they observed that the thrombocytopenic children have higher incidence of bleeding and higher mortality [18]. Another study shows higher platelet counts on admission were associated with significantly reduced risk of thrombocytopenia and survivors had higher platelet counts throughout the PICU stay than non survivors [19]. In our study the mean TPC on admission was 6.135 lakhs/cumm which is high owing to the fact that all the patients were sick and this represents a reactive phenomenon. The average TPC on day 1 significantly correlates with duration of PICU stay $\left(\mathrm{R}^{2}=0.398, \mathrm{p}<0.001\right)$ but less so with outcome $\left(\mathrm{R}^{2}=0.232, \mathrm{p}<0.05\right)$. The initial TPC and TLC significantly correlate with PICU stay, which denotes TPC is as important as TLC in predicting disease severity. A study from Taiwan on pediatric reactive thrombocytosis (platelet count $>500,000 / \mu \mathrm{L}$ ) showed a positive correlation between platelet count and WBC count and an inverse relation between platelet count and blood hemoglobin level. The same study also found that thrombocytosis is a significant independent risk factor for the length of hospital stay [20].
A study on adult population in Israel showed that thrombocytosis is a risk factor for prolonged hospitalization in adults as well; the mortality rate of patients with thrombocytosis was significantly higher than that of non-thrombocytosis patients [6] The difference in TPC (D1-D2) and (D1-D3) in this study also correlates with the duration of PICU stay and death outcome, denoting that a rapid fall in platelet count is adding to increase morbidity and mortality (Table-2). A similar outcome was reported by Agrawal S et, al [19], that drop in platelet counts $>27 \%$ and thrombocytopenia were independently related to mortality. This finding is comparable with a recent adult study with $>30 \%$ drop in platelet counts [21]. In this study a drop in platelet count observed was $>24 \%$ and $>42 \%$ by day 2 and 3 respectively which was found to be significantly associated with increased mortality $(\mathrm{P}<0.05$ in both cases). Also we observed a statistical significant correlation between $\mathrm{C}$ - reactive protein with duration of PICU stay $\left(\mathrm{R}^{2}=0.464, \mathrm{p}<0.001\right)$ and between $\mathrm{C}$ reactive protein with death of cases $\left(\mathrm{R}^{2}=0.308, \mathrm{p}<\right.$ 0.05). A strong correlation was also observed between duration of PICU stay with death outcome $\left(\mathrm{R}^{2}=0.481\right.$, $\mathrm{p}<0.001)$.

\section{Conclusion}

Total platelet count, total leucocyte count and Creactive protein during the initial periods of patient stay 
in PICU significantly correlate with death outcome and duration of stay. Significant fall in platelet count following admission is associated with increased mortality. Any significant drop in platelet count during the initial period of PICU stay, even without thrombocytopenia necessitates thorough patient evaluation. Serial measurements of platelet counts are better predictors of pediatric intensive care outcome than one-time value. This will facilitate earlier prognostication of cases. Similar studies are required with larger number of patients in the pediatric age group to further consolidate the present study findings.

\section{Compliance with Ethical Standards}

Disclosure of potential conflicts of interest: Author Dr. Swarup Kumar Bisoi declares that he has no conflict of interest. Author Dr. Subrata Palo declares that he has no conflict of interest.

Research involving human participants and/or animals: This article does not contain any studies with animals performed by any of the authors. All procedures performed during this study involving patients were in accordance with the ethical standards of the institutional research and ethical committee and with the 1964 Helsinki declaration and its later amendments or comparable ethical standards.

Informed consent: Due care was taken and informed verbal consent was obtained from the parents of the hospital admitted cases before doing their clinical examination and data collection.

\section{Contributions of the Authors:}

1. Dr. Swarup Kumar Bisoi: Developed the concept of the study, study protocol, data collection tool, piloting the study, desk review, review of literature, study design, collection of data related to the study participants and writing of report based on the study findings.

2. Dr. Mamata Devi Mohanty: Contributed in finalization of data collection tool, data cleaning, compilation, validation and analysis, also supported in report writing.

\section{What we know:}

- Increased leucocyte count and C -reactive protein is part of systemic inflammatory response.

- Platelets are critical for hemostsis.

\section{What is New}

- Platelets are important component of innate and adaptive immune system.

- Initial TPC value help earlier prognostication and allows time for intensive evaluation and intervention.

Acknowledgement: Sincere thanks to our Paediatric Intensive Care Unit in- charge staff nurse Suchismita Jena for her commendable effort during data compilation without which this work would not have been possible.

\section{Abbreviations}

D- Day, IL- Interleukin, PICU- Paediatric Intensive Care Unit, $\mathrm{R}^{2}$ - Correlation coefficient, SPSS- Statistical Package for Social Science, TLC- Total Leucocyte Count, TPC- Total Platelet Count.

Funding: Nil, Conflict of interest: Nil

Permission from IRB: Yes

\section{References}

1. Fitzgerald JR, Foster TJ, Cox D. The interaction of bacterial pathogens with platelets. Nat Rev Microbiol. 2006 Jun;4(6):445-57.

2. Vanderschueren S, De Weerdt A, Malbrain M, Vankersschaever D, Frans E, Wilmer A, et al. Thrombocytopenia and prognosis in intensive care. Crit Care Med. 2000 Jun; 28(6):1871-6.

3. Pollack MM, Patel KM, Ruttimann UE. PRISM III: an updated Pediatric Risk of Mortality score. Crit Care Med. 1996 May;24(5):743-52.

4. Hesham AA, Heba HA. Thrombocytosis at time of hospitalization is a reliable indicator for severity of CAP patients in ICU. Egypt J Chest Dis Tuberc. 2012 Jul;61(3):145-9.

5. Buss DH, Cashell AW, O'Connor ML, Richards F, Case LD. Occurrence, etiology, and clinical significance of extreme thrombocytosis: a study of 280 cases. Am J Med. 1994 Mar; 96(3):247-53.

6. Max J Coppes SI. Pediatric Thrombocytosis. Medscape News and prespectives [Internet]. 2014 Mar 31; Available from: http://emedicine. medscape.com/ article/959378-overview. 
7. Dodig S, Raos M, Kovac K, Nogalo B, Benko B, Glojnaric I, et al. Thrombopoietin and interleukin-6 in children with pneumonia-associated thrombocytosis. Arch Med Res. 2005 Apr;36(2):124-8.

8. Du X, Williams DA. Interleukin-11: review of molecular, cell biology, and clinical use. Blood. 1997 Jun 1;89(11):3897-908.

9. Yohannan MD, Higgy KE, al-Mashhadani SA, Santhosh-Kumar CR. Thrombocytosis. Etiologic analysis of 663 patients. Clin Pediatr (Phila). 1994 Jun; 33(6):340-3.

10. Dame C, Sutor AH. Primary and secondary thrombocytosis in childhood. Br J Haematol. 2005 Apr;129(2):165-77.

11. Heng JT, Tan AM. Thrombocytosis in childhood. Singapore Med J. 1998 Nov;39(11):485-7.

12. Vlacha V, Feketea G. Thrombocytosis in pediatric patients is associated with severe lower respiratory tract inflammation. Arch Med Res. 2006 Aug;37(6):755-9.

13. Othman N, Isaacs D, Kesson A. Mycoplasma pneumoniae infections in Australian children. J Paediatr Child Health. 2005 Dec;41(12):671-6.

14. Chan KW, Kaikov Y, Wadsworth LD. Thrombocytosis in childhood: a survey of 94 patients. Pediatrics. 1989 Dec;84(6):1064-7.
15. Garoufi A, Voutsioti K, Tsapra H, Karpathios T, Zeis PM. Reactive thrombocytosis in children with upper urinary tract infections. Acta Paediatr Oslo Nor 1992. 2001 Apr;90(4):448-9.

16. Robey C, Chmel H. Thrombocytosis associated with acute osteomyelitis. Infection. 1984 Dec;12(6):384-6.

17. Robert M Kliegmann, Bonita F. Stanton. Laboratory Medicine. In: Nelson Text book of Pediatrics. 20e ed. 2016. p. 3466

18. Russul FM, Adeba AA, Jasim MA. Prognostic Value of Platelet Count in Paediatric Intensive Care Unit. Medical Journal of Babylon Vol. 9 No. 4 -2012; 833- 842

19. Sachdev A, Gupta D, Chugh K, Agrawal S. Platelet counts and outcome in the pediatric intensive care unit. Indian J Crit Care Med. 2008;12(3):102.

20. Wang J-L, Huang L-T, Wu K-H, Lin H-W, Ho M$\mathrm{Y}$, Liu HE. Associations of reactive thrombocytosis with clinical characteristics in pediatric diseases. Pediatr Neonatol. 2011 Oct;52(5):261-6.

21. Strauss R, Wehler M, Mehler K, Kreutzer D, Koebnick C, Hahn EG. Thrombocytopenia in patients in the medical intensive care unit: bleeding prevalence, transfusion requirements, and outcome. Crit Care Med. 2002 Aug;30(8):1765-71.

\section{How to cite this article?}

Bisoi S. K, Mohanty MD. Prognostic significance of total platelet count with PICU outcome. Int J Pediatr Res.2016;3(6):394-399.doi:10.17511/ijpr.2016.i06.05. 